\title{
El internacionalismo latinoamericanista del PC chileno en el mundo postsoviético $(1988-1994)^{1}$
}

\author{
The Chilean Communist Paryt's Latin Americanist \\ internationalism in the post-Sovietic world (1988-1994)
}

\author{
José Ignacio Ponce López \\ Universidad de Santiago de Chile, \\ Comisión Nacional de Investigación Científica y Tecnológica, Chile \\ jose.ponce.l@usach.cl
}

\begin{abstract}
Resumen
El artículo trata sobre los cambios en el imaginario político internacionalista del Partido Comunista chileno, tras el derrumbe de la Unión de República Socialista Soviética y el inicio de la "transición" a la democracia en su país. Se sostiene que después de una profunda crisis interna y de sus referentes, el PCCh reformuló su política internacionalista, enfatizando su perspectiva latinoamericanista. Si bien esta venía desarrollándose desde antes, en particular durante los años de la Dictadura de Pinochet, la mantención de Cuba como un Estado socialista le permitió reafirmar la vigencia de su proyecto histórico y concretar nuevas formas de solidaridad con otros pueblos del continente. Ello allanó la posibilidad de que los comunistas chilenos recibieran con entusiasmo otros procesos anticapitalistas de la región, tal como fue la rebelión zapatista en México. Aunque nunca plantearon copiarla mecánicamente, los más importantes dirigentes comunistas tuvieron simpatía y atracción del proceso encabezado por el EZLN, pues les dio algunas claves de sentido para enmarcar a escala continental las movilizaciones que impulsaban en Chile contra las políticas neoliberales.
\end{abstract}

Esto se argumenta en base a periódicos, revistas, documentos partidarios y bibliografía relacionada al tema.

\section{Palabras Clave}

Comunismo; internacionalismo; latinoamericanismo; postsoviético; Chile

\footnotetext{
${ }^{1}$ Este artículo es producto del proyecto Fondecyt ${ }^{\circ} 1150583$. El autor agradece a los integrantes de dicho proyecto Rolando Álvarez, Fernando Pairicán, Jorge Navarro, Raquel Aranguez y Ximena Urtubia, por las discusiones, fuentes y manuscritos facilitados. Además, agradecemos los comentarios de los evaluadores para precisar diferentes elementos de la versión inicial.

Esta obra está sujeta a la Licencia Reconocimiento-NoComercial-CompartirIgual 4.0 Internacional de Creative Commons. http://creativecommons.org/licenses/by-nc-sa/4.0/

(cc) EY-NC-SA
} 


\begin{abstract}
The article its about the changes in the Chilean Communist Party's imaginary political internationalist, after the collapse of the Union of Soviet Socialist Republic and the beginning of the "transition" to democracy in his country. It is argued that after a deep internal crisis and its referents, the Chilean Communist Party reformulated its internationalist policy, emphasizing its Latin American perspective. Although it had been developed before, particularly during the Pinochet dictatorship, Cuba's maintenance as a socialist state allowed it to reaffirm the validity of its historic project and to establish new forms of solidarity with other peoples of the continent. This paved the way for the chilean communists to enthusiastically welcome other anticapitalist processes in the region, as was the Zapatista rebellion in Mexico. Although they did not propose to copy it mechanically, the most important communist leaders had sympathy and attraction of the process headed by the EZLN, because it gave some keys to them to frame to the continental scale the mobilizations that propelled in Chile against the neoliberal policies.

This is argued based on newspapers, magazines, partisan documents and literature related to the topic.
\end{abstract}

\title{
Keywords
}

Communism; internacionalism; Latin Americanism; post-sovietic; Chile

Eric Hobsbawm planteó que uno de los aspectos característicos del comunismo fue su "internacionalismo"2. Sin embargo, la desintegración del "socialismo real" puso en jaque dicha dimensión del imaginario político de los Partidos Comunistas (PPCC) a escala mundial. Sumado a los contextos locales, el fin de la URSS ayudó a la embestida de sus adversarios para cuestionar la vigencia del proyecto comunista. Pero tras 26 años, algunos PPCC mantienen sus banderas en alto y han logrado influir en la política de sus respectivos países, aunque con distintos grados y diversos caminos recorridos.

A pesar de que durante el siglo XX los estudios sobre el comunismo fueron variados, solo en las últimas décadas distintos historiadores han intentado posicionarlo como una realidad múltiple y compleja a lo largo del siglo $\mathrm{XX}^{3}$. Estos han permitido comprender al comunismo no como una experiencia fatalmente destinada al fracaso, sino como un campo político de diversas trayectorias específicas necesarias de historizar para dar cuenta de sus derroteros. Perspectivas que han ayudado en abordar de diversas formas el desarrollo de los PPCC tras la disolución del bloque soviético, destacando los análisis sobre los casos del PC italiano, PC francés, PC español y PC uruguayo, entre otros. Como ha resumido un historiador, por ejemplo, si el PCF fue incapaz de recuperarse de la crisis que golpeó a los PPCC luego del fin del socialismo, quedando en una marginalidad hasta el día

\footnotetext{
${ }^{2}$ Eric Hobsbawm, "Problemas de la historia comunista”, en Revolucionarios. Ensayos contemporáneos. Barcelona, Crítica, 2010.

3 Una reflexión en este sentido en Elvira Concheiro, Massimo Modonesi y Horacio Crespo, (coordinadores), El Comunismo: otras miradas desde América Latina. México, México, UNAM-CEIICH, 2007.
} 


\section{El internacionalismo latinoamericanista del PC chileno en el mundo postsoviético. (1988-1994)}

de hoy; el PCI, tras disolver su identidad y orgánica, se convirtió en un actor democrático incuestionable en la vida política italiana; mientras que el PCE y el PCU sufrieron desgajamiento y transformaciones identitarias, pero sin diluir sus denominaciones comunistas, lograron mantener incidencia en sus países, para luego alcanzar cargos institucionales importantes, particularmente en Uruguay ${ }^{4}$. Estas diferencias suelen estar vinculadas a los desarrollos locales y concretos de los PPCC, lo que trae consigo que para dar cuenta de su trayectoria en el mundo postsoviético, es necesario situarlos en su contexto, analizar las distintas dimensiones de su accionar y ver los diferentes cambios y continuidades que experimentaron. Donde uno de los aspectos que no ha sido investigado en profundidad es la cuestión del internacionalismo, que en este trabajo trataremos abordar a partir de un caso concreto: el Partido Comunista de Chile (PCCh).

Un contexto particular vivió el PCCh hacia fines de la década de 1980 y principios de los noventa. En su país, la desintegración de la URSS coincidió con la naciente "transición" de la dictadura de Pinochet a la democracia ${ }^{5}$. Esta última, marcada por un recambio donde primó una disposición hacia el "consenso" entre las dos principales coaliciones políticas de la época, cuestión que tenía como una de sus condiciones la exclusión del PCCh del sistema institucional' ${ }^{6}$. Así, desde 1990 los comunistas chilenos vivieron una experiencia histórica que combinaba un mundo postsoviético con una postdictadura en su país.

En torno al desarrollo de esta colectividad durante el periodo analizado, se han sostenido dos tesis contrapuestas. Por un lado, tras asumir la lucha armada bajo la dictadura, en 1990 habría predominado la ortodoxia ideológica y la incapacidad de entender el nuevo escenario político chileno, imposibilitando la adaptación del PCCh a este ${ }^{7}$. Desde una posición distinta, otros han planteado que el PCCh, en el mismo periodo, vivió un particular proceso de renovación, incluyendo una lenta adaptación proyectual, estratégica e, incluso, semántica al nuevo contexto democrático ${ }^{8}$.

Con este marco de los estudios sobre la experiencia reciente del comunismo a escala mundial y nacional, el siguiente artículo indaga cómo el PCCh enfrentó, al calor de su contexto local, la configuración de un mundo postsoviético y, en particular, qué sucedió con la dimensión internacionalista de su imaginario político.

\footnotetext{
${ }^{4}$ Un resumen de esta bibliografía en Rolando Álvarez, Hijas e hijos de la rebelión. Una historia social y política del Partido Comunista de Chile en postdictadura (1990-2000). [Manuscrito Inédito], 2017. Para el caso español se puede ver Luis Fernández, Cambio y adaptación en la izquierda. La evolución del Partido Comunista de España y de Izquierda Unida (1986-2000), CIS-Siglo XXI, 2004. Para uruguay, Adolfo Garcé, La política de la fe. Apogeo, crisis y reconstrucción del PCU (1985-2012), Montevideo, Fin de Siglo, 2012.

${ }^{5}$ Es extensa la literatura sobre la "transición" en Chile. Un trabajo compilatorio en Paul Drake e Ivan Jaksic, El modelo Chileno. Democracia y Desarrollo en los noventa, Santiago, LOM, 1999.

${ }^{6}$ Luis Corvalán M., Del Anticapitalismo al Neoliberalismo en Chile, Santiago, Sudamericana, 2004.

7 Alfredo Riquelme, Rojo atardecer. El comunismo chileno entre dictadura y democracia, Santiago, DIBAM, 2009.

8 Rolando Álvarez, Hijas e hijos.....op. cit.; Cristina Moyano, "El Partido Comunista y las representaciones de la crisis del carbón: La segunda renovación" en Tiempo Histórico, n 2, Santiago: Universidad Academia de Humanismo Cristiano, 2011, pp. 27-42.
} 
Un investigador del comunismo en Chile, retomando a Cornelius Castoriadis, ha planteado que el quehacer humano se despliega por medio de "imaginarios sociales" y permiten la apropiación simbólica de sus acciones. Así, los imaginarios estarían constituidos por tradiciones culturales y valóricas de una sociedad, además de ser la manera como esta es representada en determinados momentos históricos. Sumando a Tomás Moulian, esta propuesta ha propuesto que la creación cognitiva combina deseos, mitos colectivos, sueños compartidos, conocimiento científico, orientando la acción y movilizando voluntades, mezclando de esta forma aspectos subjetivos e irracionales, con otros lógicos y calculados. De allí que estarían constituidos tanto por la cultura erudita y popular de una sociedad, como por la construcción de distintos actores políticos, evidenciando su carácter social y diversificado, siendo articulados de manera específica por cada sujeto ${ }^{9}$. En resumen, los imaginarios orientan las vidas de las personas y las colectividades, pero a su vez, estas los van transformando en su devenir, haciéndose necesario historizarlos.

A partir de lo anterior, se propone en este artículo que el PCCh no renunció al internacionalismo como dimensión de su imaginario político, sino que lo reformuló enfatizando su latinoamericanismo, en el marco de una transformación más general de su proyecto partidario. Junto con hacer variaciones a sus apuestas políticas, los comunistas fueron reconstruyendo un imaginario donde se diluyeron lentamente sus aspectos soviéticos mientras se profundizó su enraizamiento nacional y latinoamericano. Si bien esto se acentúo desde 1990 en adelante, era un fenómeno que venía procesándose al menos desde el golpe de Estado de 1973, cuando se estrecharon vínculos con Cuba y la experiencia Sandinista. De tal modo, tras la caída de la URSS, los comunistas latinoamericanizaron su internacionalismo, tomando como referencia de sus reflexiones otros procesos anticapitalistas en la región, tal como ocurrió con la rebelión zapatista. Así, después del desplome soviético y ante una dura exclusión en la postdictadura chilena, los comunistas vieron a Cuba y su "periodo especial" (1990-1993), como un ejemplo de resistencia a la ofensiva neoliberal a las puertas del "imperio" y una evidencia de que no era ineludible la crisis del "socialismo". Mientras que la insurrección Zapatista (1994) les permitió procesar una crítica a la globalización y enmarcar la movilización social contra el neoliberalismo en una dinámica mundial, a través de la cual, también, emergían nuevos actores políticos, como los indígenas, tal cual ya se empezaban a expresar en Chile. Esto también estuvo acompañado por el rescate de un acervo histórico nacional del Partido y de las luchas populares, el cual hundía -según los comunistas chilenos- sus raíces en América Latina, expresándose en prácticas y discursos de los dirigentes de la colectividad.

Para dar cuenta de ello, analizaremos documentos partidarios, testimonios de dirigentes y prensa del periodo 1988-1994. La primera parte se enfoca en los vínculos latinoamericanos del PCCh antes de la caída de la URSS. Luego indaga la forma en que enfrentaron el derrumbe del "bloque soviético" y cómo reformularon

\footnotetext{
${ }^{9}$ Véase Rolando Álvarez, Hijas e hijos....op. cit.
} 


\section{El internacionalismo latinoamericanista del PC chileno en el mundo postsoviético. (1988-1994)}

su latinoamericanismo en torno a la revolución cubana. Posteriormente analizamos la recepción de la rebelión zapatista y las "enseñanzas" que sacaron los comunistas de dicho proceso. Terminamos el texto con unas conclusiones respectivas sobre el caso analizado y en torno a la cuestión del internacionalismo.

\section{El latinoamericanismo del PCCh antes de la caída de la URSS}

Salvo contadas menciones ${ }^{10}$, se ha asumido que los lazos internacionales del PCCh se constituían en torno al Movimiento Comunista Internacional guiado por la URSS. No obstante esta realidad, tampoco se puede negar los PPCC de la región tuvieron posturas propias respecto a algunos procesos políticos locales o continentales, dándose en algunas ocasiones tensiones con la propia URSS11. Tal como ha planteado una autora, ello se explica porque "el locus o espacio comunista" articuló diferentes pertenencias, donde "sin dudas, se admiraba el proceso soviético y efectivamente Moscú fue un "centro" del comunismo internacional, pero su función de centro se remitió más al plano de las ideas que al control efectivo de las periferias, que en muchos casos resultó impracticable"12. Siguiendo este planteamiento, en esa periferia estaban los PPCC latinoamericanos, entre los que "en esas yuxtaposiciones se destacó el rol del Partido nacional, como estructura organizacional principal"13. Por lo mismos, al igual que muchos de sus símiles latinoamericanos, amplios aspectos del comunismo chileno se definieron por cuestiones locales y no necesariamente por decisiones geopolíticas de la URSS. Así, la influencia soviética funcionó más para ratificar o -como han sostenido otros autores sobre la teoría "marxista ortodoxa" soviética- legitimar a posteriori la acción del $\mathrm{PCCh}^{14}$. De allí que este partido podía tener simpatías con respecto a otros movimientos populares de la región, sin estar condicionado de antemano por la política impulsada por la URSS.

Ahora bien, estas dos formas de relaciones políticas internacionales no estaban exentas de tensiones. El caso más demostrativo probablemente sea la "revolución cubana". Los comunistas chilenos tempranamente simpatizaron con el proceso sin tener claro si tomaría un "rumbo socialista", como lo confirmó en 1962,

\footnotetext{
10 Véase Claudio Pérez, "De la guerra contra Somoza a la Guerra contra Pinochet. La experiencia internacionalista revolucionaria en Nicaragua", en Claudio Pérez y Pablo Pozzi (ed.), Historia oral e Historia Política, Santiago, LOM, 2012; Viviana Bravo, ¡Con la razón y la fuerza venceremos!, Santiago, Ariadna, 2010. Una mención del tema también en Carmelo Furci, El Partido Comunista de Chile y la vía chilena al socialismo, Santiago, Ariadna, 2008.

${ }^{11}$ Una mirada sobre somera sobre esto en el ensayo de Manuel Caballero, "Tormentosa historia de una fidelidad. El comunismo latinoamericano y la URSS" en Nueva Sociedad, $\mathrm{N}^{\circ} 80$, Caracas, NUSO, 1985, p. 78-85. Disponible en: http://nuso.org/media/articles/downloads/1335 1.pdf

${ }^{12}$ Laura Prado, "Partido Comunista: Problematizar el internacionalismo", Ponencia presentada en VII Jornadas de Sociología de la ULP, 5 al 7 de diciembre 2012, La Plata. Disponible en: http://www.memoria.fahce.unlp.edu.ar/trab eventos/ev.2197/ev.2197.pdf, p. 5.

13 Ibídem.

${ }^{14}$ Luis Corvalán M. "Las tensiones entre la teoría y la práctica en el Partido Comunista en los años 60 y 70" Manuel Loyola y Jorge Rojas (comp.) Por un rojo amanecer: Hacia una historia de los comunistas chilenos, Santiago, Valus Editores, 2000.
} 
ya que significó un "triunfo sobre el imperialismo yanqui". Aunque su solidaridad no fue tan fervorosa como la de otras corrientes de izquierda de la época, más que por un mandato de la URSS y por las críticas de los cubanos al "sistema soviético" en los sesenta, las divergencias del PCCh con la isla tuvieron que ver con las distintas "vías revolucionarias" impulsadas por cada uno. Es más, incluso después que Cuba se integró al "campo socialista", las tensiones de los comunistas con la "revolución" se mantuvieron, porque esta instaló como posibilidad la insurgencia en el continente, diametralmente opuesta al camino "no armado" que impulsaba el PCCh por esos años ${ }^{15}$.

De todas formas, los comunistas chilenos tuvieron cercanía con Cuba "socialista". Existieron algunas experiencias que evidencian esta relación. Una fue la vivida por la familia Pellegrín Friedman. Los padres, dos militantes comunistas arquitectos, viajaron a colaborar en planes de construcción en la isla durante los sesenta. El golpe de estado de 1973, los encontró en la isla junto a sus hijos, entre quienes estaba Raúl Pellegrín. Otra experiencia fue la seguida por un contingente de jóvenes, dentro de quienes estaba el militante comunista de extracción popular Galvarino Apablaza, que durante el gobierno de la UP fueron a formarse como médicos y luego debían volver a contribuir a la "revolución chilena". Pellegrín y Apablaza permanecieron en Cuba los años posteriores al golpe, y ambos engrosarían las filas de los jóvenes comunistas que se formaron en la academia de oficiales cubanos, tras el ofrecimiento de Fidel Castro a la cúpula del PCCh. Estos jóvenes pasaron a cumplir la "tarea" militar y fueron parte un nuevo trayecto del internacionalismo comunista chileno ${ }^{16}$.

En efecto, de forma azarosa, fue este grupo de comunistas el germen de una experiencia tanto práctica como simbólica del internacionalismo del PCCh. Su exilio y formación militar cubana provocó que estos comunistas chilenos en la isla, se permearan de un imaginario que combinaba socialismo con un nacionalismo y latinoamericanismo. Pero más importante aún, el factor clave para estos jóvenes y el Partido sería su contribución en la "revolución nicaragüense". Tras el ingreso a las instituciones castrenses y las indecisiones del PCCh sobre cómo enfrentar a Pinochet en Chile, el mismo Fidel propuso que estos jóvenes militares colaboraran en la lucha del Sandinismo contra Somoza. Luego del derrocamiento de este último y en el marco de la reconstrucción política de Nicaragua encabezada por los sandinistas, la importancia alcanzada por los comunistas chilenos en el proceso se manifestó en su designación para relevantes espacios políticos, institucionales y militares. Así, esta experiencia de lucha y acción política se terminó transformando en una forma

\footnotetext{
${ }^{15}$ Carmelo Furci, op. cit, p. 135 y ss.

${ }^{16}$ Los trabajos testimoniales sobre el tema son variados, para este trabajo hemos utilizado Tita Friedmann, Mi hijo Raúl Pellegrín. Comandante José Miguel, Santiago, LOM, 2008 y Javiera Olivares, Guerrilla: Combatientes Chilenos en Colombia, El Salvador y Nicaragua, Santiago, CEIBO, 2017. Una investigación histórica sobre el tema en Claudio Pérez, "De la guerra..op. cit. Para un trabajo que mezcla lo testimonial con la investigación histórica, véase Luis Rojas Núñez, De la rebelión popular a la sublevación imaginada. Antecedentes de la historia política y militar del Partido Comunista de Chile y del FPMR, 1973-1990, Santiago, LOM, 2011.
} 


\section{El internacionalismo latinoamericanista del PC chileno en el mundo postsoviético. (1988-1994)}

concreta en cómo los comunistas habían ayudado a otros procesos emancipatorios. De allí que no fuera extraño que algunos comunistas chilenos luego se pusieran a disposición y participaran en las luchas populares Salvadoreñas y Colombianas ${ }^{17}$. A la postre, estas camadas de jóvenes comunistas serían conocidas en Chile simplemente como los "internacionalistas". Una experiencia que no solo mezclaba su perspectiva latinoamericana, sino que una vinculación con la lucha armada, de allí que un autor lo haya calificado como el inicio de un internacionalismo combativo en el PCCh ${ }^{18}$.

En esta misma lógica, si el apoyo de los cubanos hizo que los comunistas estrecharan su sentido de pertenencia con la isla, la lucha de los chilenos en Nicaragua también transformó a éste país en otra de sus referencias, no solo por la solidaridad entre pueblos, sino también como inspiración para la lucha que desplegaban los comunistas contra otra dictadura en Chile. Más cuando varios de esos internacionalistas tras el triunfo en Nicaragua, fueron llamados a regresar a su Chile y para ser parte de la dimensión armada de la Política de Rebelión Popular de Masas (PRPM) de los comunistas contra Pinochet. Su experiencia no solo fue una cuestión que cargó de mística y simbolismo el accionar de los comunistas chilenos, sino que también nutrió los debates y la acción misma del PCCh durante los ochenta $^{19}$. Por eso, los años 1990 y 1991 no fueron solo impactantes por el derrumbe de la URSS y la caída del "Muro de Berlín", sino que también por la derrota Sandinista en las urnas ${ }^{20}$.

A pesar de esta reformulación que vivía en la práctica su internacionalismo, los comunistas chilenos mantuvieron un vínculo estrecho con el "bloque soviético". Desde el día del golpe de Estado, también la URSS y la RDA habían prestado su apoyo a los militantes exiliados del PCCh. Esto confirmó para muchos comunistas chilenos la solidaridad, hermandad e internacionalismo de dichos países. Una gran cantidad de militantes de la izquierda chilena sobrevivirían e, incluso, se formarían profesionalmente en dichos países. Aunque sin mellar las críticas de algunos comunistas a la realidad social y política que vivieron, los países soviéticos continuaron jugando una importancia gravitante en el imaginario político de la colectividad.

Por lo mismo, la Perestroika y la situación crítica que vivió la URSS hacia finales de los ochenta fueron reflexionadas por el PCCh. El momento de análisis más consistente de la organización se dio al calor de su XV Congreso, cuando se hicieron públicas sus conclusiones sobre las deficiencias de la URSS y apoyaron "con toda decisión la "revolución dentro de la revolución" impulsada por Mijail Gorbachov. Estimándolo "el hecho más trascendental en la historia revolucionaria de las últimas

\footnotetext{
17 Aunque no se ha tratado historiográficamente en profundidad la participación comunista en estos procesos, algunas referencias aparecen en Luis Rojas Núñez, De la rebelión...op. cit. y Javiera Olivares, Guerrilla..op. cit.

${ }^{18}$ Luis Rojas Núñez, De la rebelión..op. cit. En particular, véase la segunda parte de su trabajo.

19 Viviana Bravo, ¡Con la razón... op. cit.; Rolando Álvarez, Arriba los del mundo, Santiago, LOM, 2011.

20 Javiera Olivares, Guerrilla..op. cit.
} 
décadas, que debe redundar en más socialismo y más democracia"21. Esto, según el PCCh, permitiría "rectificar errores y desviaciones del período stalinista y de los años de estagnamiento", por lo que reafirmaban: "Creemos en la democracia y creemos en el socialismo, que, a pesar de todos sus problemas, constituye el más grande progreso de los pueblos y de la humanidad hacia un mundo de justicia social, hacia la creación de una sociedad más humana". Así, la Perestroika -para el PCChsignificaba el desarrollo combinado de socialismo con democracia ${ }^{22}$.

No obstante lo positivo de este proceso de cambios, la Perestroika tenía márgenes de incertidumbre, por lo mismo que los comunistas chilenos ponían ciertos "cortafuegos" y relativizaban la "crisis del socialismo": "la renovación es una necesidad permanente. Asumirla encierra un deber ineludible para los revolucionarios. Pero ella tiene expresiones particulares en cada país socialista, acorde con su desarrollo histórico y sus propias realidades". Evidenciando cierta limitación para ver la globalidad del problema en los países del bloque socialista, planteaban los matices que existían por ejemplo con "la República Democrática Alemana, es una prueba de la capacidad del socialismo para responder a los grandes desafíos de la época contemporánea, garantizando a su población un buen nivel de vida y distinguiéndose por su alta tecnología, por su capacidad productiva y por sus exitosos índices de desarrollo en diversos campos". Mientras que otros casos, como Cuba, "enfrentada a problemas, en gran parte derivados del bloqueo imperialista de treinta años y a otras causas, emprende un proceso activo de rectificación encabezado por el Partido Comunista de Cuba". Su síntesis era: "los países socialistas atraviesan, sin duda, por dificultades. Pero éstas se dan en distintas intensidades y formas requiriendo, por lo tanto, diversas soluciones en concordancia con un principio que consideramos de obligatoria aplicación práctica: la edificación del socialismo debe llevarse a cabo teniendo rigurosamente en cuenta las condiciones de cada nación y cada Partido Comunista debe tener primero en consideración sus propias realidades" 23 .

Por tanto, para los comunistas el intento de "renovación" de los revolucionarios, particularmente bajo los regímenes del "socialismo real", era una cuestión a la cual se plegaban. Por lo mismo apoyaron la Peresotrika impulsada por Gorbachov y los diversos intentos de "rectificación" en los países socialistas. Más aún, como han dado cuenta otras investigaciones, también asumieron la tesis de la "renovación revolucionaria" como un objetivo del Partido para reformular su proyecto político para Chile ${ }^{24}$. De esta manera, la Perestroika fue asumida inicialmente como una inspiración para oxigenar el proyecto comunista en la URSS y Chile, pero que no debía aplicarse como una "copia mecánica". Sin embargo, la crisis cada vez más aguda y el derrumbe finalmente de la mayoría de los países del

\footnotetext{
${ }^{21}$ Partido Comunista de Chile, Informe XV Congreso del Partido Comunista de Chile, Santiago, El Siglo Editores, p. 15.

22 Ibídem.

${ }^{23}$ Ibíd., p. 37

${ }^{24}$ Rolando Álvarez, Arriba los... op. cit.
} 


\section{El internacionalismo latinoamericanista del PC chileno en el mundo postsoviético. (1988-1994)}

bloque soviético, derivó en que los comunistas fueran haciendo precisiones sobre el proceso y su perspectiva para Chile, acercándose hacia la "revolución cubana" y alejándose de la URSS.

\section{"El Periodo Especial" del PCCh: la caída de la URSS y la solidaridad con}

\section{Cuba}

El XV Congreso del Partido Comunista finalizó hacia mediados del 1989. Una de las experiencias de "socialismo real" que los comunistas rescataban para matizar el incierto camino que vivía la URSS, era la República Democrática Alemana (RDA). Pero noviembre de ese mismo año terminaría con la "caída del muro de Berlín" y el inicio de la reunificación alemana. Ello evidenció la aceleración de la crisis de los distintos países del "socialismo real", que el PCCh no desconoció durante el año 1989 , como lo mostraron una serie de Seminarios, libros y reportajes publicados en sus órganos de prensa para analizar la "crisis del socialismo"25. Sin embargo, el contraste de la reflexión en el informe de 1988 y lo que ocurrió un año después con la RDA, daba cuenta de lo limitado de la lectura del PCCh sobre los problemas que vivían los países socialistas.

Este complejo escenario para los referentes internacionales del PCCh, se combinó a nivel nacional con una crisis interna del partido, el cual venía atenazado por su exclusión de la transición. Los adversarios políticos impugnaron al PCCh que los cambios en los "socialismos reales" evidenciaban el fracaso de su proyecto histórico a escala planetaria. Antiguos aliados e incluso militantes del partido asumieron la necesidad de una reestructuración profunda del proyecto socialista, donde la democracia se volvía central. Algunos militantes del PCCh, además, utilizaron dicho planteamiento como argumento para legitimar su rechazo a la política que había aplicado el partido bajo la dictadura y que generó profundas diferencias internas. Toda esta situación derivó en una diáspora de una buena cantidad de sus militantes ${ }^{26}$. En fin, tanto la situación internacional como nacional parecía indicar el declive del proyecto al que apuntaban los comunistas chilenos.

A pesar de esto, una franja importante decidió continuar en la organización. Pero los militantes del PCCh que se mantuvieron en la colectividad no fueron agentes que se negaron a ver la realidad política que se desplegaba a su alrededor y se encerraron en los dogmas para sobrevivir. Tal como ya habían anunciado en su XV Congreso, ellos asumían "renovar" su proyecto político, pero sin bajar las banderas del comunismo. De allí que apuntaron a una "renovación revolucionaria",

\footnotetext{
25 Véanse, VV.AA, Crítica y socialismo: una reflexión desde Chile, Santiago, Ediciones CISPO, 1989; VV.AA, Crisis y renovación, Ediciones Medusa-ICAL, 1990.

26 Es imposible cuantificar la "crisis" del PCch durante 1990. Se ha señalado que, si bien al Comité Central del Partido renunciaron solo 3 integrantes de un total de 40 y otros 2 fueron sancionados, en la JJCC el impacto fue más grande: el $40 \%$ de su CC renunció. De todas maneras, hay coincidencia que el mayor vaciamiento del PCch se dio en su base. Eso sí, la colectividad hacia finales de 1990 logró las 60.000 firmas de apoyo para legalizarse, duplicando el mínimo exigido por la ley. Un detalle de la crisis en Rolando Álvarez, Hijas e hijos...op. cit.
} 
pero gradual. Este aggiornamiento incluyó la reformulación de su imaginario político, entre ellos, sus referencias internacionales.

El cambio que vivió el imaginario político del PCCh, podríamos decir, combinó dos aspectos centrales: "nacionalización" de su historia y "latinoamericanización" de sus referencias políticas internacionales ${ }^{27}$. Ambos elementos venían sedimentándose desde hace un tiempo atrás. El primer venía planteándose como reflexión política y estaba profundamente engarzado con los postulados de un sector de los "renovadores" del PCCh, que asumían que la política del partido históricamente había estado condicionada por la realidad del país y no por las definiciones de agentes internacionales. En tal sentido, un amplio espectro de la organización cambio la fecha de fundación del PCCh de 1922 -cuando había asumido el nombre de Partido Comunista- a 1912, instalando que la historia de la organización partía con la fundación del Partido Obrero Socialista, al alero del obrero Luis Emilio Recabarren ${ }^{28}$. Esto no era menor, pues permitía a los comunistas dotarlos de una historicidad propia y que respondía a la historia de Chile, distinta a los derroteros de la Revolución Rusa y los que había seguido el régimen soviético. De allí que no fuera extraño cuando en junio de 1990, al momento de desarrollarse la Conferencia Nacional partidaria para salir de la crisis y la "discusión ensimismada", el PCCh cerrara sus conclusiones con que "hoy más que nunca tiene sentido retornar a nuestras raíces históricas y reconocer como fecha de nacimiento de nuestra organización el 4 de junio de 1912"29. En el acto de cierre de la Conferencia, realizado a solo un par de días del 4 de junio, Volodia Teitelboim -a la sazón Secretario General- dejaba entrever el espíritu de esta decisión: "El Partido no se va a diluir, no se va a dividir", agregando "el hecho que se establezca como fecha de fundación del Partido el 4 de junio de 1912 no es un acto simbólico. Tiene un profundo sentido político, ideológico, humano, chileno, latinoamericano"30. Se situaba así, el inicio de la historia del PCCh ya no en la Revolución Rusa, sino que en la realidad de las luchas populares chilenas y latinoamericanas.

Mientras se desataba en toda su magnitud la crisis de los "socialismos reales" europeos, los comunistas optaron por llevar a cabo uno de las ideas que circuló fuertemente en el XV Congreso, a saber, "debemos afianzar la disposición de nuestro Partido a mantener y estrechar relaciones con todas las fuerzas revolucionarias y democráticas latinoamericanas"31. Por un lado, el PCCh aportó en la mantención de las redes de los PPCC latinoamericanos, participando en conferencias, reuniones y

\footnotetext{
27 Un estudio sobre esto en las JJCC, en Fernando Pairican, "La gran crisis: Las Juventudes Comunistas de Chile defendiendo su identidad en tiempos de transición y renovación democrática, 1989-1992", en Izquierdas, $\mathrm{N}^{\circ} \quad 30$, octubre 2016, pp. 124-160. Disponible en: http://www.scielo.cl/pdf/izquierdas/n30/art05.pdf

28 Una investigación detallada sobre esto en Jorge Navarro, "Volviendo a los orígenes. La reconfiguración política-cultural del Partido Comunista de Chile y el rescate de los fundadores (19881990)", [Artículo Inédito], 2017.

${ }^{29}$ Partido Comunista de Chile, Conferencia Nacional, 1990, Santiago, El Siglo Editores pg. 59.

30 Pluma y Pincel, 7 de junio de 1990, p. 6. Cursivas nuestras.

31 Partido Comunista de Chile, Informe al XV Congreso, op. cit, p. 41. Subrayado nuestro.
} 


\section{El internacionalismo latinoamericanista del PC chileno en el mundo postsoviético. (1988-1994)}

actos de solidaridad conjuntos ${ }^{32}$. Pero también, por otro, entre enero y agosto de 1990, se hicieron cada vez más presentes las referencias a Latinoamérica y Cuba en los discursos y medios de comunicación del PCCh. Volodia Teitelboim hizo especial referencia a los pueblos de Martí y Sandino -léase Cuba y Nicaragua- en su discurso en el Estadio Santa Laura de enero de 1990, donde los comunistas salían oficialmente a la luz pública en un acto de miles de personas, todavía bajo la dictadura de Pinochet. La venida de Silvio Rodríguez en marzo de 1990, durante los primeros días del naciente gobierno de Aylwin, referenció todavía más la cultura cubana en el imaginario de la izquierda chilena y, en especial, de los comunistas. En tal sentido, "la Conferencia Nacional reiteró la necesidad de que nuestro Partido desarrolle en profundidad una política latinoamericanista que, asentándose en nuestras raíces históricas, dé mayor contenido y particularidad a nuestra gesta liberadora, humanista y democrática, en la perspectiva del socialismo que queremos para Chile"33. Lo cual cobró más relevancia cuando se ratificó un diagnostico que venía planteándose un año antes: "el Tercer Mundo, América Latina en particular, somos las mayores víctimas del modelo de funcionamiento del capitalismo", que solo se podía "enfrentar y derrotar tales designios con la unidad de sus pueblos asentada en la herencia común de Bolívar, O’Higgins y Martí, de Sandino, Mariátegui, Recabarren y Allende". Remarcando que "el espíritu de Cuba es un ejemplo para América Latina. Hoy, una vez más, es objeto de una tremenda presión del imperialismo, ante lo cual renovamos nuestra decidida solidaridad con el pueblo cubano y su Partido Comunista"34. De tal manera, en el marco de una de sus mayores crisis como partido y cuando los socialismos europeos comenzaban a derrumbarse, el PCCh retomó su historia nacional y las luchas populares del continente como referencias de su imaginario.

Fue en los meses de julio y agosto de 1990 cuando los comunistas chilenos prendieron las alarmas sobre la crisis de la URSS y definieron solidarizar totalmente con el pueblo cubano. A través de sus medios de comunicación aparecieron permanentemente tanto reportajes en torno a la vida cotidiana en Cuba, sobre figuras emblemáticas (como el Che) o hechos significativos (el 26 de julio), como entrevistas a intelectuales cubanos, dirigentes de la isla y del PCCh, además de reproducir los principales discursos de Fidel Castro. El intento por difundir lo que pasaba en Cuba llegó a tal punto, que los comunistas distribuyeron el periódico cubano "Granma" en Chile.

Las muestras de apoyo también fueron presenciales, participando con una delegación encabezada por las principales figuras del PCCh, Volodia Teitelboim y Gladys Marín en la conmemoración del 26 de julio en Cuba. A su regreso, Gladys dio

\footnotetext{
32 Para el caso del PCCh, el apoyo de los otros PPCC en años del exilio fue clave para articular una infraestructura política en países cercanos que ayudarán a la reorganización en el interior y exterior. Si bien no hay estudios, los lazos con el PC argentino se estrecharon de manera sustantiva, dado el establecimiento de muchos chilenos y chilenas entre los setenta y ochenta en su país vecino. Algunas referencias testimoniales de esto en el libro de Javiera Olivares, Guerrilla...op. cit.

${ }^{33}$ Partido Comunista de Chile, Conferencia Nacional..op. cit, p. 58.

34 Ibídem.
} 
una entrevista que sería publicada en la edición de agosto de "Pluma y Pincel", donde partía sentenciando y endosándole una centralidad estratégica a la isla: "yo creo que en Cuba se está jugando, a nivel mundial, la opción del socialismo"35. En paralelo, el periódico "El Siglo" publicó un reportaje de Juan Andrés Lagos, donde se citaba una parte del discurso de Fidel Castro, donde reflexionaba sobre la crisis del socialismo: “¿Y ante esto, cuál debe ser la actitud de nuestro pueblo?...¿Cuál debe ser la actitud de nuestro partido, de los militantes revolucionarios, de los comunistas, de los patriotas, de los millones de mujeres y hombres de honor?;LA DE LUCHAR, LUCHAR, LUCHAR, LA DE RESISTIR, RESISTIR!". Agregando: "porque EL SOCIALISMO NO ES UNA OPCIÓN COYUNTURAL...EL SOCIALISMO ES UNA NECESIDAD HISTÓRICA INSOSLAYABLE". Rematando con la consigna: "socialismo o muerte" 36.

No tenemos la certeza qué provocaron estas palabras de Gladys Marín y Fidel Castro en la militancia comunista chilena en aquellos complejos días de julio y agosto de 1990. Cuando se difundieron estos planteamientos se desplegaban los momentos más agudos de la crisis del PCCh, donde la incertidumbre sobre el devenir de la colectividad se tomada el partido. Probablemente a quienes se mantuvieron en el PCCh, las palabras de Fidel y Gladys debieron hacerles sentido. Al menos para la Dirección comunista chilena las palabras de Fidel ratificaban la necesidad de ir a contrapelo de lo que decían sus adversarios históricos en el país, otorgándole un discurso y algunas respuestas para sobrellevar la crisis política, proyectual y orgánica en la cual estaba sumergida la colectividad. El ejemplo de Cuba, la misma isla que les permitió sobrevivir en el exilio y formar a jóvenes para enfrentar a Pinochet, les daría respaldo para mantener la bandera del socialismo en alto, enfatizando la inserción latinoamericana de la historia del PCCh. Por ello, si los cubanos habían podido resistir 30 años la agresión norteamericana a solo kilómetros de esta potencia geopolítica, ¿por qué no podrían resistir los comunistas en Chile el avance de sus adversarios?

Tras la migración de varios militantes del Partido y su juventud, los comunistas se embarcaron en desplegar su "renovación revolucionaria" y su política latinoamericanista. En tal sentido, buscaron las raíces de la historia de lucha popular en el continente. Tomando como referencia la conmemoración de los 500 años de la invasión española, el PCCh a través de su revista "Pluma y Pincel" dedicó decenas de artículos, reportajes y columnas al análisis de la historia y actualidad del continente. Textos de intelectuales de la talla de Noam Chomsky, Heinz Dietrich, Adolfo Sánchez Vásquez, Mario Benedetti y Eduardo Galeano, entre otros, reflexionaban sobre dichos tópicos en la publicación. Uno de los ejercicios más interesantes fue, siguiendo a Sánchez Vásquez, relevar a los marxistas y pensadores críticos de América Latina. En tal tarea destacó el militante del PCCh y filósofo, Osvaldo Fernández, quien difundió el marxismo de Mariátegui. Otro aspecto fue la

35 Pluma y Pincel, agosto de 1990, p. 4.

${ }^{36}$ El Siglo, 29 de julio al 4 de agosto de 1990, p. 12. Negritas y mayúsculas en el original. 


\section{El internacionalismo latinoamericanista del PC chileno en el mundo postsoviético. (1988-1994)}

importancia que le dieron los comunistas chilenos a las luchas de los pueblos indígenas, por lo que rescataron desde su resistencia al imperio español y lo vincularon con las luchas actuales que estos pueblos mantenían en distintas partes del continente.

Pero además de estos elementos más reivindicativos de orden históricos, los comunistas chilenos tomaron como una de sus principales banderas el apoyo y la solidaridad con el pueblo cubano. Una expresión fue la petición al gobierno de Aylwin de restablecer las relaciones diplomáticas con la isla, que si bien no rindió frutos, se mantuvo varios años como una reivindicación del PCCh. Otra forma fue la defensa irrestricta en 1991 de Cuba, cuando se terminó por derrumbar la URSS. En efecto, tras la entronización de Yeltsin y el fin de las relaciones de este país con la isla, el PCCh estableció como elemento central de su internacionalismo la defensa de la revolución cubana. Con la crisis soviética se decretó el "periodo especial en tiempo de paz" en la isla, lo que se agudizó por las presiones de EEUU y el nuevo embargo aplicado en 1992. Al ver esto, los comunistas chilenos sostuvieron que la solidaridad debía "pasar a la concreta", planteando que "cuando el hostigamiento imperialista a Cuba se torna cada día y cada hora más peligroso, nuestra solidaridad con el pueblo y el Gobierno cubano constituye un deber moral de primer orden". Por lo mismo y en consonancia con lo que sucedía en otros países, impulsaron una serie de "Comités de Amigos" o "Casas de la Amistad" con Cuba en distintas ciudades del país, que desplegaron movilizaciones, denunciaron la "agresión yanqui" y recolectaron insumos de primera necesidad para enviar a la isla. Finalmente, los comunistas interpelaron al gobierno chileno que apoyara ante la ONU, la OEA y otras instancias, el fin al bloqueo de Cuba ${ }^{37}$.

Aunque sin mayores réditos, los comunistas chilenos estrecharon sus vínculos ideológicos y morales con la isla, que además les sirvió para materializar en acciones concretas el internacionalismo latinoamericanista de la colectividad. Aunque, al menos desde los ochenta se venía fraguando una perspectiva internacionalista más enraizada en el continente, fue tras el derrumbe de la URSS en 1991 cuando se expresó de manera práctica. Si 1989 y 1990 sirvió para que los comunistas chilenos pudieran mantener algunas banderas políticas e ideológicas en torno a su proyecto socialista, tomando como ejemplo de lucha, resistencia y rectificación a la experiencia cubana; desde 1991 en adelante, las acciones de solidaridad hicieron material ese imaginario internacionalista. De esta manera, la crisis política del PCCh y de su referente histórico la URSS, permitió abrir la puerta hacia un imaginario latinoamericanista de los comunistas, el cual se profundizó con otros procesos políticos posteriores, tales como la rebelión zapatista.

\section{¡Zapata vive! El PCCh y la rebelión zapatista.}

${ }^{37}$ El Siglo, 6-12 de octubre, 1991, p. 5. 
Aunque el PCCh vivió a inicio de 1990 su "propio periodo especial en tiempo de paz", marcado por una crisis orgánica, política y proyectual, entre 1992 y 1993 trató de salir lentamente de la posición arrinconada en la que se encontraba. Excluidos de la institucionalidad por el sistema electoral y la marginación de las principales alianzas políticas, los comunistas desplegaron su accionar en los movimientos sociales. En tal sentido, a fines de 1991 el PCCh pasó de una independencia crítica a la oposición del gobierno de Aylwin, impulsando diferentes movilizaciones para intentar incidir en el escenario nacional. Para ello, recuperó posiciones en las principales organizaciones sociales del país, particularmente entre los trabajadores y el estudiantado universitario. El correr de los años demostró que fue una estrategia con cierto rédito, ya que a mediados de la década el PCCh encabezó algunas de las principales organizaciones sindicales ${ }^{38}$ y estudiantiles ${ }^{39}$. Sin embargo, a nivel político electoral los frutos fueron bastante escasos, puesto que el frente de izquierda que intentaron reconstituir si bien tuvo cierto avance en las municipales de 1992, cayó drásticamente en las presidenciales y parlamentarias de $1993^{40}$. De esta manera, los comunistas chilenos aun cuando recuperaron parte de influencia social, no habían podido romper la exclusión del sistema político binominal. De allí que las coaliciones políticas hegemónicas vieran con cierta indiferencia al PCCh durante estos años.

Empero, los comunistas chilenos seguían tratando de adecuarse al nuevo contexto político y reconstruir su proyecto. Ello abarcó -entre otras cosas- el desarrollo de un análisis político-social del neoliberalismo y la elaboración de una estrategia para "rebelarse" a él. En dicho marco, el movimiento zapatista que emergió en México al iniciarse 1994, otorgó algunas claves de sentido a la acción que impulsaban los comunistas chilenos por esos años.

El PCCh manifestó sus primeras grandes reflexiones sobre el mundo postsoviético de cara a su XVI Congreso de 1994. En el Informe a esta instancia se identificó como "neoliberalismo" al modelo económico, social y político impulsado en gran parte del planeta, al alero de la expansiva influencia de EE.UU. El Consenso de Washington, la Conferencia de Santa Fe II, el acuerdo del NAFTA, junto a los incipientes Tratados de Libre Comercio, para los comunistas, reflejaban que "en la actualidad el enemigo principal es el capital transnacional, los grandes grupos económicos internos aliados o fundidos a él y el poder militar, que actúa a través de

\footnotetext{
38 José Ponce y Rolando Álvarez, “¿Comunismo después del fin del comunismo? La política sindical del Partido Comunista de Chile en la postdictadura chilena (1990-2010)", en Nuestra Historia, Fundación de Investigaciones Marxistas, Madrid, 2016, pp. 100-115. Disponible en: https://revistanuestrahistoria.files.wordpress.com/2016/12/nh n1 2016 autorinvitado.pdf

${ }^{39}$ Luis Thielemann, "Hijos de Recabarren, hijos de la transición. Sobre las JJCC y la anomalía estudiantil de los '90. En Rolando Alvarez y Manuel Loyola, Un trébol de cuatro hojas. Las Juventudes Comunistas de Chile en el siglo XX. Santiago, Ariadna-América en Movimiento, 2014

40 Sobre la trayectoria electoral del PCch en la posdictadura véase: José Ponce, "Adaptación e inclusión de la Izquierda revolucionaria en las transiciones democráticas de Uruguay, Chile y Argentina. Una mirada desde el desempeño electoral, 1983-2009", en Izquierdas, N 18, 2013. Disponible en: https://revistanuestrahistoria.files.wordpress.com/2016/12/nh n1_2016 autorinvitado.pdf
} 


\section{El internacionalismo latinoamericanista del PC chileno en el mundo postsoviético. (1988-1994)}

un conjunto de medidas de fuerza, por medios políticos, económicos, comunicacionales para imponer y mantener su dominación" ${ }^{41}$. El nuevo reparto del mundo producto de esto, hundía al continente en una enorme desigualdad, pues si en el norte estaba la principal potencia mundial, "América Latina forma parte de ese Tercer Mundo cuya situación se torna cada vez más aflictiva", generando "un clima de descontento masivo, que estalla en alzamientos callejeros". Y aun cuando las clases dominantes "ante el incremento de la indignación de los movimientos reivindicativos y la extensión de la protesta de los pobres responden con más y más mistificaciones a través de los medios de comunicación, sumadas a la represión diaria", había cierta cuota de esperanza para los comunistas, ya que "el mundo no se detiene. Una de sus manifestaciones es la emergencia de bloques progresistas en diversos países. Se constituyen tanto en Europa Occidental como Oriental, en América Latina, Asia, África. Se reorganizan los comunistas y las fuerzas de avanzada". Demostrándose en las elecciones que se realizarían en Brasil y México, donde "grandes movimientos populares aspiran allí al poder. Algo semejante acontece en Uruguay con el Frente Amplio. En Argentina una coalición nueva, el Frente Grande, obtiene -hecho inédito- a buena distancia la primera mayoría en Buenos Aires y avanza en otras regiones del país. Centro América no es extraña a este proceso de recuperación de fuerzas populares. Ahí están el Frente Farabundo Martí en El Salvador y el Sandinismo en Nicaragua". Con sus particularidades, los comunistas concluían que crecían las corrientes progresistas, ya no solo como movimientos testimoniales, pues representaban "clases sociales, la inmensa marea dispersa que se va organizando gradualmente y entra al combate desde México hasta Chile, formando parte de ese sector mayoritario de la humanidad que está mal, reclama un cambio a su situación miserable y se esfuerza por lograrlo", donde "un importante denominador común para todos los pueblos de América Latina es la defensa de su soberanía e identidad"42. A partir de esto último, terminaban por rescatar la emergencia de las luchas campesinas e indígenas en Guatemala, Colombia, Ecuador, Perú, Bolivia, Brasil y, sobre todo, la rebelión zapatista de México. Desde su perspectiva, estos últimos habían confrontado directamente el poder transnacional que pretendía consolidarse con el TLCAN. Esto explicaba porque, en abril de 1994, los comunistas calificaron a la rebelión zapatista como la primera revolución del siglo XXI.

El análisis sobre la "rebelión en Chiapas", se nutría del acercamiento concreto que tuvo Gladys Marín en México con el proceso encabezado por el EZLN. En febrero de 1994, se dio una reunión de varios PPCC del continente, en la cual participó la dirigente en representación del partido chileno. Su viaje incluyó un recorrido por el Estado Chiapas. Probablemente la irrupción del movimiento zapatista le recordó a

\footnotetext{
41 Todas las citas en Partido Comunista de Chile, Informe al XVI Congreso del Partido Comunista de Chile, Santiago, El Siglo Editores, 1994, p. 19-21. En un inicio el Congreso siguió la numeración desde que pasó a llamarse Partido Comunista (1921), pero al final la instancia sumó los congresos del POS, convirtiéndose en el XX Congreso.

${ }^{42}$ Partido Comunista de Chile, Informe al XVI Congreso..op. cit., p. 21-22.
} 
Gladys, y a toda una generación de comunistas, su lucha al calor de la PRPM. Esta experiencia explica porque, en el marco de una reunión continental de Partidos Comunistas y Obreros para discutir "La lucha ideológica y los Pueblos en América Latina ante el siglo XXI", ella se vio como la única que cuestionó que dichas colectividades no discutieran como tema central la sublevación zapatista. Gladys Marín recordó así esta situación años más tarde: "Esto era una locura, estar discutiendo temas tan "profundos" a espaldas de la realidad. Planteé mi opinión en la reunión y los compañeros del Partido Socialista Popular de México, que tenían una posición crítica al fenómeno de Chiapas, sin embargo me facilitaron un viaje a ese Estado"43. No era extraño que los PPCC fueran reacios a una forma de lucha armada, pues históricamente pusieron reparos a este tipo de acciones en la región. Lo menos común era que una dirigente comunista mostrara tal interés, como fue el caso de Marín en dicha ocasión.

Gladys Marín escribió algunas de sus apreciaciones al calor de su viaje por Chiapas y que fueron publicadas en el periódico partidario "El Siglo". En sus escritos de la época sentenció que los zapatistas habían "irrumpido para mostrar que la política neoliberal ha traído más miseria, más desigualdad". Ello no podía continuar, sosteniendo la dirigenta "que hay que levantarse y luchar. La exigencia de democracia y libertad tiene que levantar a los pueblos en nuevas revoluciones" 44 . Así, la lucha del naciente EZLN revitalizó la posibilidad de la revolución y "clavó el grito de dignidad y estremeció al neoliberalismo mexicano y continental" 45 . Pero evidenciando el aprendizaje del pasado y cierta heterodoxia sobre las experiencias que parecían exitosas, una Editorial del periódico oficial del PCCh, sentenció: "Sin duda alguna, los tiempos de la copia, de imitar modelos, de seguir políticas a ojos cerrados se terminaron, y felizmente nunca más volverán. Esa misma libertad y a la vez exigencia, es lo que nos compromete de razón y sentimiento, de solidaridad y convicción histórica a escudriñar a fondo en Chiapas, a conocer, analizar, y actuar"46. Este sentido de solidaridad, pero ante todo analítico de la experiencia zapatista puede explicar porque los escritos de Gladys y las reflexiones del PCCh se centraron en dar cuenta de las causas del proceso y las formas organizativas de las comunidades en Chiapas, pero sin el objetivo de copiarlas mecánicamente, como reiteraban de forma permanente.

Pero esto no solo fue una atracción coyuntural, pues años más tarde -cuando se distanció más el EZLN de los partidos de izquierda mexicanos- Gladys sostuvo planteamientos similares. En forma retrospectiva, Marín a inicios de la década del 2000, cuando ya llevaba casi 10 años como máxima dirigente del PCCh, rescató distintas "enseñanzas" de la sublevación zapatista. En primer lugar, para ella, "los hechos de Chiapas dejaron al desnudo la frivolidad y ridiculez de los gobernantes de América Latina que proclamaron como un éxito el "ingreso de México al Primer

\footnotetext{
${ }^{43}$ Gladys Marín, La vida es hoy, Santiago, Don Bosco, 2002, p. 231.

${ }^{44}$ El Siglo, del 26 de marzo al 1 de abril, 1994, p. 3.

45 Ibídem.

${ }^{46}$ Ibídem.
} 


\section{El internacionalismo latinoamericanista del PC chileno en el mundo postsoviético. (1988-1994)}

Mundo". En tiempos donde muchos dejaban de creer en el socialismo o incluso en un proyecto distinto al neoliberalismo, para Gladys, "Chiapas es una respuesta a tanto oportunista, a tanto demagogo, a tanto pontífice de la renovación, del modernismo que creen que la pobreza y la desigualdad no existen o, si existe, son para montar shows en torno a la superación de una pobreza que ellos mismos agudizan cada día".47

Segundo, sostenía Marín, para los movimientos revolucionarios y progresistas Chiapas dejó en claro que "la fuerza es el elemento central de toda nueva opción política", la cual se construía "con organización y muchas luchas, que se van concatenando y conducen, a medida de su profundización, a crisis políticas que provocan rupturas del sistema". Además de esta concepción procesual de la lucha política, Gladys Marín remarcaba el elemento subjetivo para la acción: "en la crisis está implícito entender que hay condiciones objetivas para ella.... pero no bastan. Tienen que estar la voluntad de los que encabezan los sindicatos, los partidos políticos, de cambiar esta situación. Tenemos que saber aprovechar los momentos que se crean para provocar una ruptura en el sistema, para que entren los elementos democráticos y pueda haber un cambio". Esta actitud voluntariosa, según Marín, "nos demuestra también que, cuando sucede un hecho importante, se crea de inmediato un nuevo escenario político". En base a esta lógica e invocando claramente la piedra angular de la PRPM del PCCh, no era ajeno que rematara: "por último, nos enseña que todas las formas de lucha son válidas". Estas nociones de fuerza, acción voluntaria y ruptura política (no necesariamente armadas), que habían sido los supuestos de la PRPM ${ }^{48}$, se mantuvieron en la base de la política de "Revolución Democrática” que el PCCh consagró en su Congreso de 1994, justo meses después de desatarse la "rebelión en Chiapas"49.

Una tercera lección de los zapatistas fue el rescate de la movilización y presión social: "Chiapas nos enseña que a los gobiernos, a los parlamentos, a los empresarios, se les obliga y no se les suplica; se los obliga a cumplir con promesas y programas, a respetarnos en nuestra condición social o ideológica”. Si lo trasladamos al Chile de la época, era un claro guiño crítico a la disposición al "consenso" político que imperó en el país y la reivindicación de la lucha social para el avance de los movimientos populares. Además, sumaba la impugnación de los comunistas a la institucionalidad política, cuestión que se entiende en el marco de la exclusión que vivían en Chile: "nos muestra que los procesos electorales, en la mayoría de los países, son viciados, porque hay fraudes encubiertos o descarados, o porque son excluyentes y no reflejan el verdadero sentir de un pueblo". Finalmente, en tiempos donde todos se consideraban de "clase media" y se negaba la relevancia de los sectores populares, Gladys los reivindicaba: “Chiapas nos da una lección de identidad, de pobres que se reconocen como pobres y que son capaces de levantarse

\footnotetext{
47 Gladys Marín, La vida es... op. cit.pg. 240

48 Véanse los trabajos de Rolando Álvarez, Arriba los pobres..op. cit; y Viviana Bravo, ;Con la razón...op. cit.

49 Sobre esta política, véase Rolando Álvarez, Hijas e hijos de....op. cit.
} 


\section{José Ignacio Ponce López}

en defensas de sus derechos"50. Por todo esto, en base a la rebelión zapatista, Gladys sentenciaba "en este siglo las luchas no hacen más que comenzar y el desenlace depende de la voluntad y de la actitud combativa de los pueblos. América Latina tiene un papel en la historia y tiene una deuda con sus raíces, con los pueblos originarios, que nunca han dejado de darnos grandes lecciones". Estas reflexiones evidenciaban claramente un espíritu similar -al menos retóricamente- en el cual se desarrolló el "internacionalismo combativo"51 y "latinoamericanista" de los comunistas en los ochenta. La importancia para Marín sobre el proceso, la principal líder comunista en la postdictadura, sintetizando que "llegar a Chiapas dejó en mí una impresión de por vida"52.

Al llegar Gladys de México, "El Siglo" dedicó varias páginas a la rebelión zapatista. No solo se publicaron sus columnas escritas mientras recorría Chiapas, sino que también editoriales del PCCh y reportajes centrales del proceso. Se rescató, además, la figura de Emiliano Zapata como uno de los luchadores populares de la historia del continente que los comunistas reconstruían en su desplazamiento cada vez más acentuado hacia el "latinoamericanismo". La misma tónica siguió "Pluma y Pincel", donde se hizo una entrevista a Gladys Marín sobre el tema, que se sumó a los análisis de importantes intelectuales y militantes de izquierda sobre la realidad de la izquierda Latinoaméricana tras la acción del EZLN. Los comunistas llegaron al punto de publicar un libro que recopilaba los discursos del "Subcomandante Marcos" con reflexiones de su ya Secretaria General sobre la rebelión. Con esta clara política de acercamiento de los comunistas al proceso encabezado por el EZLN, no fue extraño que los militantes quisieran conocerlo, incluyeran a "Marcos" dentro de sus referentes icónicos, usaran poleras con su imagen, colgaran fotos con los zapatistas caminando en la Selva Lacandona o viajaran -como buena parte de los izquierdistas de todo el planeta- a conocer Chiapas, la cuna de la rebelión contra el neoliberalismo. Ya los comunistas no solo tenían a Cuba como referente latinoamericano, sino que los zapatistas habían mostrado caminos para que los revolucionarios avanzaran en el siglo XXI, pero tal como dijera José Carlos Mariátegui, no como calco y copia, sino como creación heroica.

\section{Conclusiones}

El fin del siglo XX fue un escenario complejo para los comunistas chilenos. La llegada de un régimen político democrático por el cual habían luchado durante 17 años, los terminó marginando de la institucionalidad por un sistema electoral excluyente y unas alianzas políticas que lo vetaban. Esto vino acompañado por la crisis de sus principales referentes internacionales, entre ellos la URSS, la RDA, la tambaleante situación que vivió Cuba y la derrota electoral del Sandinismo en Nicaragua. Así, se hundió en el cuestionamiento de la vigencia misma de su proyecto.

\footnotetext{
50 Gladys Marín, La vida es....op. cit., pg. 234.

${ }^{51}$ Luis Rojas, De la rebelión...op. cit.

${ }^{52}$ Ibídem.
} 


\section{El internacionalismo latinoamericanista del PC chileno en el mundo postsoviético. (1988-1994)}

Muchos comunistas chilenos dejaron de militar por diferentes motivos, pero otros se mantuvieron en la colectividad.

Ante esta situación, el PCCh reformuló gradualmente su proyecto, incluyendo su imaginario político, donde la dimensión internacionalista jugaba un rol importante. Situaron el derrumbe de los "socialismos reales" en Europa del Este y no necesariamente en todo el planeta, permitiéndoles rescatar la experiencia cubana como una expresión de la vigencia del socialismo. Reforzando los lazos que habían desarrollado en los setenta y ochenta, desplegaron su solidaridad con la revolución cubana, ayudándola en lo que pudieron para mantenerla con vida en los años del "periodo especial". A través de ella, reflotaron certezas y retomaron aspectos que no habían profundizado lo suficiente en su trayectoria como partido: el rescate de su historia nacional y sus vínculos con Latinoamérica. En ese marco optaron por transformar una serie de referencias simbólicas y prácticas para reformular su internacionalismo, pero ahora acentuando su clave latinoamericanista. Así se acercaron más al pasado y presente del continente. Por lo mismo, entre 1993 y 1994 se allanó el camino para que los comunistas chilenos vieran con mucho entusiasmo la rebelión zapatista. Pero también, este imaginario latinoamericanista ayudó a los comunistas a enfrentar sus propias coyunturas nacionales. Con ello, hacia mediados de la década de 1990, el PCCh tuvo una política internacional latinoamericanista y una perspectiva en su imaginario político bastante consistente, que reemplazaba sus antiguas referencias soviéticas por otros del continente, permitiéndoles creer que durante el siglo XXI otro mundo socialista podía ser posible.

Sobre esta experiencia quedan aún varias interrogantes por indagar. Por un lado, cuáles fueron los discursos y prácticas que desplegó el PCCh en torno a otros procesos latinoamericanos, como la revolución bolivariana o el altermundismo que emergió hacia finales de la década de 1990. Por otro, cómo se fueron configurando nuevas lecturas sobre "lo político" y "lo social" que emergieron de esas experiencias, y cómo influyeron la práctica política de los PPCC en el siglo XXI. Pero además de ello, cómo se desplegaron sus lazos y redes con otros PPCC de la región desde los noventa en adelante, y si entre ellos se pudo configurar una política "internacionalista" en conjunto tras el derrumbe soviético, por solo nombrar algunos aspectos.

En tal sentido, esta primera aproximación al internacionalismo latinoamericanista del PCCh en una época postsoviética releva algunas cuestiones de esta dimensión. Estudiar el internacionalismo comunista, tal como ha señalado una autora, que articula "espacios nacionales, regional latinoamericano, local e internacional, debe tener en cuenta que un punto de mira transnacional no es excluyente sino compatible y complementario de los estudios culturales nacionales" 53. Con esto se pueden flexibilizar y relativizar las lógicas esquemáticas donde los PPCC nacionales aparecían como "periferias" pasivas del "centro" soviético". Si las

53 Laura Prado, “Problematizar el.... op. cit. p. 8. 
historias locales de los PPCC han contribuido a cuestionar profundamente estas ópticas, la historización de fenómenos transnacionales y las formas de apropiación de los comunistas a nivel local de los sucesos en otras partes del orbe, pueden consolidar como campo de estudio el problema del internacionalismo. Por lo que dar cuenta de los conflictos, contradicciones y flujos de influencia y desarrollo de este aspecto, pueden volverse parte de un campo fértil para la historiografía del comunismo en el siglo XXI.

\section{Bibliografía}

Rolando Álvarez, Hijas e hijos de la rebelión. Una historia social y política del Partido Comunista de Chile en postdictadura (1990-2000). [Manuscrito Inédito], 2017.

Rolando Álvarez, Arriba los pobres del Mundo. Santiago, LOM, 2011.

Viviana Bravo, ¡Con la razón y la fuerza venceremos!, Santiago, Ariadna, 2010.

Manuel Caballero, "Tormentosa historia de una fidelidad. El comunismo latinoamericano y la URSS" en Nueva Sociedad, N 80, Caracas, NUSO, 1985, p. 78-85. Disponible en: http://nuso.org/media/articles/downloads/1335 1.pdf

Elvira Concheiro, Massimo Modonesi y Horacio Crespo (coordinadores), El Comunismo: otras miradas desde América Latina. México, México, UNAM-CEIICH, 2007.

Paul Drake e Ivan Jaksic, El modelo Chileno. Democracia y Desarrollo en los noventa. Santiago, LOM, 1999.

Luis Corvalán M., Del Anticapitalismo al Neoliberalismo en Chile, Santiago, Sudamericana, 2004.

Luis Corvalán M. "Las tensiones entre la teoría y la práctica en el Partido Comunista en los años 60 y 70" en Manuel Loyola y Jorge Rojas (comp.) Por un rojo amanecer: Hacia una historia de los comunistas chilenos, Santiago, Valus Editores, 2000.

Luis Fernández, Cambio y adaptación en la izquierda. La evolución del Partido Comunista de España y de Izquierda Unida (1986-2000), Madrid, CIS-Siglo XXI, 2004.

Tita Friedmann, Mi hijo Raúl Pellegrín. Comandante José Miguel, Santiago, LOM, 2008

Carmelo Furci, El Partido Comunista de Chile y la vía chilena al socialismo, Santiago, Ariadna, 2008. 


\section{El internacionalismo latinoamericanista del PC chileno en el mundo postsoviético. (1988-1994)}

Adolfo Garcé, La política de la fe. Apogeo, crisis y reconstrucción del PCU (1985-2012), Montevideo, Fin de Siglo, 2012.

Eric Hobsbawm, "Problemas de la historia comunista", en Revolucionarios. Ensayos contemporáneos. Barcelona, Crítica, 2010.

Cristina Moyano, "El Partido Comunista y las representaciones de la crisis del carbón: La segunda renovación" en Tiempo Histórico, $\mathrm{n}^{\circ} 2$, Santiago: Universidad Academia de Humanismo Cristiano, 2011, pp. 27-42.

Jorge Navarro, "Volviendo a los orígenes. La reconfiguración política-cultural del Partido Comunista de Chile y el rescate de los fundadores (1988-1990)", [Artículo Inédito], 2017.

Javiera Olivares, Guerrilla: Combatientes Chilenos en Colombia, El Salvador y Nicaragua, Santiago, CEIBO, 2017.

Fernando Pairicán, "La gran crisis: Las Juventudes Comunistas de Chile defendiendo su identidad en tiempos de transición y renovación democrática, 1989-1992", en Izquierdas, $\mathrm{N}^{\circ} 30$, octubre 2016, pp. 124-160

José Ponce, “Adaptación e inclusión de la Izquierda revolucionaria en las transiciones democráticas de Uruguay, Chile y Argentina. Una mirada desde el desempeño electoral, 1983-2009", en Izquierdas, $\mathrm{N}^{\circ} 18,2013$. Disponible en: https://revistanuestrahistoria.files.wordpress.com/2016/12/nh n1 2016 autorin vitado.pdf

José Ponce y Rolando Álvarez, “¿Comunismo después del fin del comunismo? La política sindical del Partido Comunista de Chile en la postdictadura chilena (19902010)", en Nuestra Historia, Madrid, Fundación de Investigaciones Marxistas, 2016, pp. 100-115. Disponible en: https://revistanuestrahistoria.files.wordpress.com/2016/12/nh n1 2016 autorin vitado.pdf

Claudio Pérez, "De la guerra contra Somoza a la Guerra contra Pinochet. La experiencia internacionalista revolucionaria en Nicaragua", en Claudio Pérez y Pablo Pozzi (editores), Historia oral e Historia Política, Santiago, LOM, 2012.

Laura Prado, "Partido Comunista: Problematizar el internacionalismo", Ponencia presentada en VII Jornadas de Sociología de la ULP, 5 al 7 de diciembre 2012, La Plata.

Disponible en: http://www.memoria.fahce.unlp.edu.ar/trab eventos/ev.2197/ev.2197.pdf 
Alfredo Riquelme, Rojo atardecer. El comunismo chileno entre dictadura y democracia, Santiago, DIBAM, 2009.

Luis Rojas Núñez, De la rebelión popular a la sublevación imaginada. Antecedentes de la historia política y militar del Partido Comunista de Chile y del FPMR, 1973-1990, Santiago, LOM, 2011.

Luis Thielemann, "Hijos de Recabarren, hijos de la transición. Sobre las JJCC y la anomalía estudiantil de los '90", en Rolando Álvarez y Manuel Loyola, Un trébol de cuatro hojas. Las Juventudes Comunistas de Chile en el siglo XX. Santiago, AriadnaAmérica en Movimiento, 2014.

\section{Fuentes}

Gladys Marin, La vida es hoy, Don Bosco, 2002.

VV.AA, Crítica y socialismo: una reflexión desde Chile, Santiago, Ediciones CISPO, 1989.

VV.AA, Crisis y renovación, Ediciones Medusa-ICAL, 1990.

Documentos

Partido Comunista de Chile, Informe XV Congreso del Partido Comunista de Chile, Santiago, El Siglo Editores, 1989.

Partido Comunista de Chile, Conferencia Nacional, Santiago, El Siglo Editores, 1990. Partido Comunista de Chile, Informe XVI Congreso del Partido Comunista de Chile, Santiago, El Siglo Editores, 1994.

Periódicos y revistas

El Siglo, 1989-1994

Pluma y Pincel, 1988-1994

Recibido: 06/06/2017

Evaluado: $23 / 07 / 2017$

Versión Final: 15/08/2017 